\title{
Efficacy and safety of lipegfilgrastim compared with placebo in patients with non-small cell lung cancer receiving chemotherapy: post hoc analysis of elderly versus younger patients
}

\author{
Constantin Volovat ${ }^{1} \cdot$ Igor Bondarenko $^{2}$ • Oleg Gladkov ${ }^{3}$ - Anton Buchner ${ }^{4}$ • \\ Andreas Lammerich ${ }^{4}$ - Udo Müller ${ }^{4}$ - Peter Bias ${ }^{4}$
}

Received: 11 December 2015 / Accepted: 10 July 2016 / Published online: 8 August 2016

(C) Springer-Verlag Berlin Heidelberg 2016

\begin{abstract}
Purpose Lipegfilgrastim, a glycoPEGylated recombinant granulocyte colony-stimulating factor (G-CSF), reduces neutropenia duration and febrile neutropenia $(\mathrm{FN})$ incidence in patients with cancer receiving myelosuppressive chemotherapy. A phase 3 trial of lipegfilgrastim was conducted in patients with advanced non-small cell lung cancer (NSCLC) receiving cisplatin/etoposide (which produces mild-to-moderate myelosuppression). Because patients aged $>65$ years are at higher risk for FN versus younger patients, this post hoc analysis compared outcomes in elderly ( $>65$ years) versus younger participants in this trial.

Methods Patients were randomized 2:1 to receive a once-percycle single subcutaneous injection of lipegfilgrastim $6 \mathrm{mg}$ or placebo, with up to 4 cycles of every-3-week cisplatin (day 1) and etoposide (days 1-3). The primary end point was FN incidence during cycle 1 . Outcomes were compared across treatment groups and by age groups ( $\leq 65$ and $>65$ years).

Results For patients aged $\leq 65$ years, FN incidence during cycle 1 was similar in the lipegfilgrastim and placebo groups ( 3.0 vs $3.2 \%$, respectively), whereas for elderly patients, there
\end{abstract}

Constantin Volovat

cvolovat@yahoo.com; constantin.volovat@victoria-hospital.ro

1 Centrul de Oncologie Medicala, Vasile Conta 2 Str, 700106 Iasi, Romania

2 Dnipropetrovsk State Medical Academy, City Clinical Hospital N 4, 31, Blizhnaya str, Dnipropetrovsk 49102, Ukraine

3 Chelyabinsk Regional Clinical Oncology Dispensary, 42, Blukhera str, Chelyabinsk, Russian Federation 454087

4 Teva ratiopharm, Merckle GmbH, Graf-Arco-Strasse 3, 89079 Ulm, Germany was a reduction in $\mathrm{FN}$ incidence with lipegfilgrastim ( 0 vs $13.3 \%$, respectively). In both age subgroups, lipegfilgrastim showed a propensity to reduce the incidence and duration of severe neutropenia, time to absolute neutrophil count (ANC) recovery, and depth of ANC nadir. Adverse events were generally similar between groups.

Conclusions This analysis suggests that in patients with a higher FN risk, such as the elderly patients of this study, lipegfilgrastim reduces not only the duration of severe neutropenia but also the incidence of FN.

Keywords Neutropenia $\cdot$ Non-small cell lung cancer . Recombinant granulocyte colony-stimulating factor · Elderly . Phase 3 clinical trial

\section{Background}

An estimated $60 \%$ of all malignancies occur in patients $>65$ years of age, and the number of elderly patients with cancer will increase as life expectancy increases and the population ages $[1,2]$. In the USA, a $67 \%$ increase in the incidence of all cancers is anticipated for older adults $(\geq 65$ years of age), and the percentage of all cancers diagnosed in elderly adults is expected to increase from 61 to $70 \%$ by the year 2030 [3].

Without prophylactic therapy, patients receiving myelosuppressive chemotherapy for cancer may develop neutropenia or febrile neutropenia (FN), defined as an absolute neutrophil count (ANC) of $<0.5 \times 10^{9} / \mathrm{L}$ (grade 4 neutropenia) with fever, generally defined as an oral body temperature $\geq 38.3$ or $\geq 38.0{ }^{\circ} \mathrm{C}$ for at least $1 \mathrm{~h}$ at the same time as the low ANC level $[4,5]$. Neutropenia presents an increased risk of serious or life-threatening infections and is a major dose-limiting 
toxicity for many chemotherapy regimens [4]. Patients aged $>65$ years are likely to have more comorbidities and take more medications than younger patients, placing them at greater risk than younger patients for developing myelosuppression and neutropenia, the duration of which may reduce survival [1]. Elderly patients are also at increased risk for infections in the presence or absence of neutropenia [2].

Recombinant granulocyte colony-stimulating factors (G$\mathrm{CSFs}$ ) promote the proliferation and differentiation of neutrophils in patients receiving myelosuppressive chemotherapy who are at risk for FN. G-CSFs are recommended in treatment guidelines as prophylaxis for reducing the duration of severe neutropenia (DSN) in patients at a $\geq 20 \%$ risk of developing FN [4-6]. G-CSFs have been shown to reduce toxicities associated with myelosuppressive chemotherapy, including FN, in older patients [7, 8]. Lipegfilgrastim, a glycoPEGylated GCSF, is approved by the European Medicines Agency for reducing the duration of neutropenia and the incidence of FN in adults treated with cytotoxic chemotherapy for malignancy (with the exception of chronic myeloid leukemia and myelodysplastic syndromes) [9]. The safety and efficacy of lipegfilgrastim have been demonstrated in clinical trials in patients with breast cancer $[10,11]$ and non-small cell lung cancer (NSCLC) [12]. In a phase 3 trial in patients with NSCLC, there was no significant difference in the primary end point of FN incidence between lipegfilgrastim and placebo during cycle 1 (2.4\% for lipegfilgrastim vs $5.6 \%$ for placebo; $p=0.1151$ ); however, significant benefits with lipegfilgrastim were seen with respect to severe neutropenia, including a lower incidence (41.4 vs $80.0 \%$, respectively; $p<0.0001$ ) and reduced duration (mean 0.6 vs 2.3 days, respectively; $p<0.0001$ ) [12]. To provide an experimental setting that would allow for a placebo control arm from an ethical standpoint, all patients in this trial received cisplatin plus etoposide, an effective combination chemotherapy regimen for NSCLC known to produce only mild to moderate myelotoxicity, and not necessarily requiring primary G-CSF prophylaxis according to best practice guidelines [12].

The objective of the following post hoc analysis was to evaluate the efficacy and safety of lipegfilgrastim in an elderly subgroup from this phase 3 trial by stratifying patients according to age ( $\leq 65$ and $>65$ years) [12].

\section{Methods}

This was an age-based, post hoc, subgroup analysis of patients who had participated in a phase 3 multicenter, multinational, double-blind, randomized, and placebo-controlled trial (controlled-trials.com identifier ISRCTN55761467). Full details of the study design and the primary results have been reported elsewhere [12]. In brief, eligible patients were adults (aged $\geq 18$ years) who were scheduled to receive 4 cycles of cisplatin/etoposide as first-line therapy for stage IIIb/IV NSCLC and had an Eastern Cooperative Oncology Group performance status $\leq 2$, ANC of $\geq 1.5 \times 10^{9} / \mathrm{L}$, platelet count $\geq 100$ $\times 10^{9} / \mathrm{L}$, and adequate hepatic, renal, and cardiac function. Patients with an individual high risk of FN according to the assessment of the investigator (with consideration of risk factors such as age $>65$ years, low performance status, poor nutritional status, and liver, renal, or cardiovascular disease) were to be excluded from this placebo-controlled study because of ethical considerations. Within 6 months prior to randomization, patients must have had no exposure to G-CSF products (including filgrastim, pegfilgrastim, lenograstim, or investigational agents).

Patients were randomized 2:1 to receive a once-per-cycle single subcutaneous fixed dose injection of lipegfilgrastim $6 \mathrm{mg}$ or placebo [12]. Patients received intravenous (IV) cisplatin $80 \mathrm{mg} / \mathrm{m}^{2}$ (over at least $1 \mathrm{~h}$ ) on day 1 and IV etoposide $120 \mathrm{mg} / \mathrm{m}^{2}$ (over at least $1 \mathrm{~h}$ ) on days 1 to 3 every 3 weeks, for a maximum of 4 cycles. Study medication was injected subcutaneously on day 4 of each chemotherapy cycle (approximately $24 \mathrm{~h}$ after the last chemotherapy infusion).

Prior to each subsequent cycle, patients were required to have an ANC of $\geq 1.5 \times 10^{9} / \mathrm{L}$ and a platelet count of $\geq 100 \times 10^{9} / \mathrm{L}$, or the next cycle was to be postponed. Dose delays of up to 2 weeks were allowed, after which time patients were required to withdraw from the study [12]. Patients experiencing FN were to receive prophylactic open-label treatment with lipegfilgrastim during further chemotherapy cycles (irrespective of double-blind assignment) and were not to be withdrawn from the study unless deemed necessary by the investigator. Other G-CSF products were not allowed during study participation, and the randomized treatment was not to be unblinded in these patients with documented FN.

Safety was evaluated via assessment for adverse events (AEs) until 3 weeks after the last dose of study medication. Blood samples for hematology and clinical chemistry testing were obtained on day 15 of each cycle.

The primary efficacy end point was the incidence of $\mathrm{FN}$ in cycle 1 of cisplatin/etoposide chemotherapy; FN was defined as ANC $<0.5 \times 10^{9} / \mathrm{L}$ with oral body temperature of $>38.5^{\circ} \mathrm{C}$ on $\geq 2$ consecutive measurements $\geq 60$ min apart, or neutropenic sepsis, or serious or life-threatening neutropenic infection [12]. Severe neutropenia was defined as grade 4 neutropenia with ANC $<0.5 \times 10^{9} / \mathrm{L}$, and the time to ANC recovery was defined as the time from any post-chemotherapy day with ANC $<2 \times 10^{9} / \mathrm{L}$ to the first day with ANC $\geq 2 \times 10^{9} / \mathrm{L}$. Data were analyzed and are reported herein for the intent-to-treat (ITT) population, defined as all patients who were randomized at the baseline visit (including those with major protocol violations). $P$ values of $\mathrm{FN}$ in the lipegfilgrastim $6 \mathrm{mg}$ and placebo groups were calculated for patients $\leq 65$ and $>65$ years of age. $P$ values and estimates served an informational role only.

Independent ethics committees reviewed and approved the study protocol, and the study was conducted in accordance with 
the principles of the Declaration of Helsinki and the International Council for Harmonization Good Clinical Practice guidelines. Written informed consent was obtained from all patients before the start of any study-related procedures.

\section{Results}

\section{Patient disposition}

Overall, 427 patients were screened at 72 centers in 8 European countries (Belarus, Bosnia-Herzegovina, Bulgaria, Poland, Romania, Russia, Serbia, and Ukraine). Of these, 376 $(88.1 \%)$ patients were randomized (1 randomized erroneously). The ITT population comprised 375 patients $(n=250$ lipegfilgrastim; $n=125$ placebo). A total of 57 patients $(22.8 \%)$ in the lipegfilgrastim group and 31 patients $(24.8 \%)$ in the placebo group were $>65$ years old. The safety population comprised 248 patients who had received lipegfilgrastim and 125 patients who had received placebo under double-blind conditions [12].

Patient demographics and baseline disease characteristics, as summarized in Table 1, were similar between the treatment groups for patients aged $\leq 65$ years $(n=292)$ and $>65$ years $(n=83)$. Over $80 \%$ of patients were male in each treatment group and in each age group. In the overall patient population, $60.8 \%$ of patients in each treatment group had stage IV NSCLC. In the group of patients $>65$ years old, 57 patients $(68.7 \%)$ were aged 66 to 70 years, 22 patients $(26.5 \%)$ were aged 71 to 75 years, and 4 patients $(4.8 \%)$ were aged $>75$ years.

In the overall ITT population, 250 patients $(66.7 \%)$ completed the study (169 [67.6\%] lipegfilgrastim patients; 81 [32.4\%] placebo patients). When stratified by age, approximately half of the patients $>65$ years of age received all 4 chemotherapy cycles (Table 2). Dose delays were more frequent in the placebo group versus the lipegfilgrastim group in both age groups, but dose reductions and omissions were infrequent in both treatment groups, irrespective of age.
Table 1 Patient demographics and baseline characteristics (ITT population)

\begin{tabular}{|c|c|c|c|c|}
\hline \multirow[b]{2}{*}{ Variable } & \multicolumn{2}{|c|}{$\leq 65$-year population } & \multicolumn{2}{|c|}{$>65$-year population } \\
\hline & $\begin{array}{l}\text { Placebo } \\
n=95\end{array}$ & $\begin{array}{l}\text { Lipegfilgrastim } \\
n=197\end{array}$ & $\begin{array}{l}\text { Placebo } \\
n=30\end{array}$ & $\begin{array}{l}\text { Lipegfilgrastim } \\
n=53\end{array}$ \\
\hline \multicolumn{5}{|l|}{ Age } \\
\hline Mean (SD), year & $55.3(6.7)$ & $55.2(6.9)$ & $69.4(2.9)$ & $69.4(2.8)$ \\
\hline \multicolumn{5}{|l|}{ Sex, $n(\%)$} \\
\hline Female & $15(15.8)$ & $24(12.2)$ & $5(16.7)$ & $6(11.3)$ \\
\hline Male & $80(84.2)$ & $173(87.8)$ & $25(83.3)$ & $47(88.7)$ \\
\hline \multicolumn{5}{|l|}{ Weight } \\
\hline Mean (SD), kg & $70.7(13.0)$ & $70.2(13.3)$ & $69.5(14.7)$ & $64.6(10.3)$ \\
\hline$\leq 60 \mathrm{~kg}, n(\%)$ & $24(25.3)$ & $49(24.9)$ & $10(33.3)$ & $21(39.6)$ \\
\hline$>60-\leq 75 \mathrm{~kg}, n(\%)$ & $42(44.2)$ & $82(41.6)$ & $11(36.7)$ & $24(45.3)$ \\
\hline$>75 \mathrm{~kg}, n(\%)$ & $29(30.5)$ & $66(33.5)$ & $9(30.0)$ & $8(15.1)$ \\
\hline \multicolumn{5}{|l|}{ NSCLC stage at enrollment, $n(\%)$} \\
\hline Stage IIIB & $31(32.6)$ & $75(38.1)$ & $18(60.0)$ & $22(41.5)$ \\
\hline Stage IV & $64(67.4)$ & $122(61.9)$ & $12(40.0)$ & $30(56.6)$ \\
\hline Unknown & 0 & 0 & 0 & $1(1.9)$ \\
\hline $\begin{array}{l}\text { Time since diagnosis, mean (SD), } \\
\text { months }\end{array}$ & $2.8(6.9)$ & $2.2(6.1)$ & $5.4(14.1)$ & $2.8(6.4)$ \\
\hline \multicolumn{5}{|l|}{ ECOG performance status, $n(\%)$} \\
\hline 0 & $15(15.8)$ & $22(11.2)$ & $4(13.3)$ & $6(11.3)$ \\
\hline 1 & $75(78.9)$ & $157(79.7)$ & $21(70.0)$ & $37(69.8)$ \\
\hline 2 & $5(5.3)$ & $18(9.1)$ & $5(16.7)$ & $10(18.9)$ \\
\hline \multicolumn{5}{|l|}{ Reason for chemotherapy, $n(\%)$} \\
\hline Adjuvant therapy & $14(14.7)$ & $25(12.7)$ & $7(23.3)$ & $10(18.9)$ \\
\hline Metastatic disease & $81(85.3)$ & $172(87.3)$ & $23(76.7)$ & $43(81.1)$ \\
\hline \multicolumn{5}{|l|}{ Lung cancer surgery, $n(\%)$} \\
\hline No & $73(76.8)$ & $170(86.3)$ & $25(83.3)$ & $45(84.9)$ \\
\hline Yes & $22(23.2)$ & $27(13.7)$ & $5(16.7)$ & $8(15.1)$ \\
\hline
\end{tabular}

ECOG Eastern Cooperative Oncology Group, ITT intent-to-treat, NSCLC non-small cell lung cancer, $S D$ standard deviation 
Table 2 Chemotherapy cycles administered by treatment group

\begin{tabular}{|c|c|c|c|c|c|c|c|c|}
\hline & \multicolumn{4}{|c|}{$\leq 65$-year population } & \multicolumn{4}{|c|}{$>65$-year population } \\
\hline & \multicolumn{2}{|c|}{ Placebo } & \multicolumn{2}{|c|}{ Lipegfilgrastim } & \multicolumn{2}{|c|}{ Placebo } & \multicolumn{2}{|c|}{ Lipegfilgrastim } \\
\hline & $n$ & $n(\%)$ & $n$ & $n(\%)$ & $n$ & $n(\%)$ & $n$ & $n(\%)$ \\
\hline \multicolumn{9}{|c|}{ Patients completing chemotherapy cycles } \\
\hline 1 & 95 & $95(100.0)$ & 197 & $197(100.0)$ & 30 & $30(100.0)$ & 53 & $53(100.0)$ \\
\hline 2 & 95 & $85(89.5)$ & 197 & $172(87.3)$ & 30 & $24(80.0)$ & 53 & $49(92.5)$ \\
\hline 3 & 95 & $73(76.8)$ & 197 & $147(74.6)$ & 30 & $19(63.3)$ & 53 & $43(81.1)$ \\
\hline 4 & 95 & $64(67.4)$ & 197 & $140(71.1)$ & 30 & $17(56.7)$ & 53 & $31(58.5)$ \\
\hline \multicolumn{9}{|c|}{ Patients with chemotherapy delays } \\
\hline Cycle 2 & 85 & $54(63.5)$ & 172 & $49(28.5)$ & 24 & $17(70.8)$ & 49 & $14(28.6)$ \\
\hline Cycle 3 & 73 & $45(61.6)$ & 147 & $62(42.2)$ & 19 & $16(84.2)$ & 43 & $18(41.9)$ \\
\hline Cycle 4 & 64 & $46(71.9)$ & 140 & $61(43.6)$ & 17 & $15(88.2)$ & 31 & $8(25.8)$ \\
\hline \multicolumn{9}{|c|}{ Patients with chemotherapy dose reductions/omissions } \\
\hline Cycle 2 & 85 & 0 & 172 & $2(1.2)$ & 24 & $1(4.2)$ & 49 & $1(2.0)$ \\
\hline Cycle 3 & 73 & $2(2.7)$ & 147 & $1(0.7)$ & 19 & $1(5.3)$ & 43 & $1(2.3)$ \\
\hline Cycle 4 & 64 & $1(1.6)$ & 140 & $4(2.9)$ & 17 & $1(5.9)$ & 31 & $0(0)$ \\
\hline
\end{tabular}

\section{Efficacy}

\section{Incidence of $F N$}

Among patients aged $\leq 65$ years, there was no difference in the incidence of FN during cycle 1 in the lipegfilgrastim group compared with the placebo group (3.0 vs $3.2 \%$, respectively; Table 3$)$. Fewer patients aged $>65$ years receiving lipegfilgrastim $6 \mathrm{mg}(0 / 53 ; 0 \%)$ had FN during cycle 1 compared with placebo $(4 / 30 ; 13.3 \%)$ (Table 3$)$.

\section{Incidence and duration of severe neutropenia}

In patients aged $\leq 65$ years, the incidence of severe neutropenia during cycle 1 was higher in the placebo group than in the lipegfilgrastim group (56.8 vs $27.6 \%$, respectively; Table 3 ). In patients aged $>65$ years, there was a smaller difference in the incidence of severe neutropenia during cycle 1 relative to that observed in patients aged $\leq 65$ years: $66.7 \%$ with placebo compared with $49.1 \%$ with lipegfilgrastim (Table 3 ).

In patients aged $\leq 65$ years, the mean DSN during cycle 1 in the lipegfilgrastim group was 0.6 days compared with 2.1 days in the placebo group (Table 3). Similarly, in patients aged $>65$ years, mean DSN during cycle 1 in patients receiving lipegfilgrastim was shorter (1.0 days) than DSN in patients receiving placebo (3.0 days) (Table 3 ).

\section{Time to ANC recovery}

In patients aged $\leq 65$ years, the mean time to ANC recovery during cycle 1 in the lipegfilgrastim group was 6.8 days compared with 13.3 days in the placebo group (Table 3). These findings were similar to those in patients aged $>65$ years, in whom time to ANC recovery during cycle 1 was shorter in those receiving lipegfilgrastim $6 \mathrm{mg}$ (6.5 days) compared with those receiving placebo (12.2 days) (Table 3 ).

\section{Depth of ANC nadir}

The mean depth of the ANC nadir during cycle 1 in the lipegfilgrastim group was higher $\left(1.6 \times 10^{9} / \mathrm{L}\right)$ than that in the placebo group $\left(0.7 \times 10^{9} / \mathrm{L}\right)$ in patients aged $\leq 65$ years, as well as in patients aged $>65$ years $\left(1.5 \times 10^{9} / \mathrm{L}\right.$ and $0.5 \times 10^{9} / \mathrm{L}$, respectively; Table 3 ).

\section{Safety}

The most common AEs are summarized in Table 4. Overall, the incidence of AEs was generally similar between lipegfilgrastim and placebo treatment groups in patients aged $\leq 65$ years and those aged $>65$ years. In both age groups, the most common AEs were alopecia, anemia, nausea, and neutropenia. Comparing the elderly and younger lipegfilgrastim recipients, the percentage of patients experiencing any $\mathrm{AE}$ was generally higher for elderly patients than for younger patients.

\section{Discussion}

A post hoc analysis was conducted in elderly patients with NSCLC who participated in a phase 3 trial of lipegfilgrastim, a once-per-cycle glycoPEGylated G-CSF. Patients with a high individual risk of FN were excluded. For this reason, unlike a 


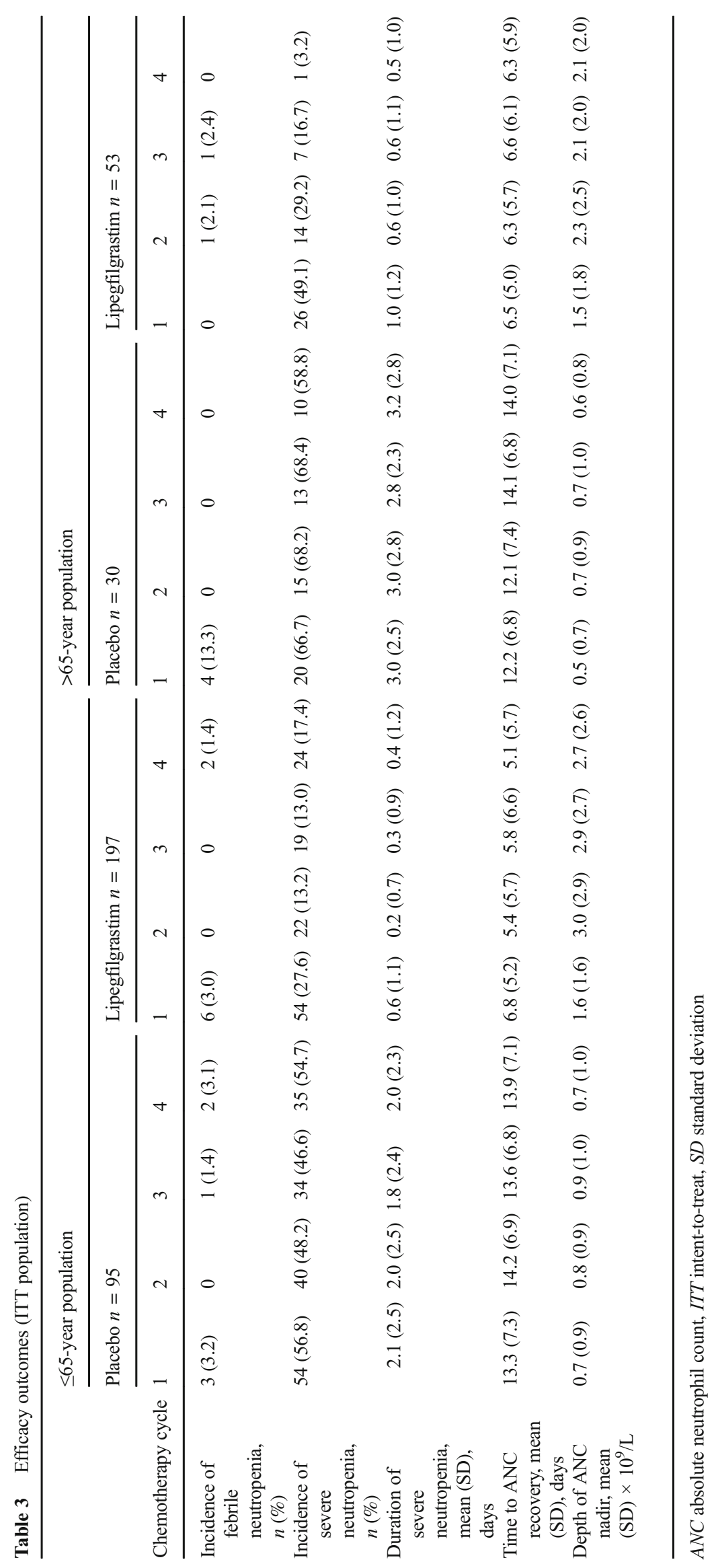


Table 4 Most frequent adverse events (occurring in $\geq 5 \%$ of lipegfilgrastim recipients in any category)

\begin{tabular}{|c|c|c|c|c|c|c|c|c|}
\hline \multirow[b]{3}{*}{ Adverse event } & \multicolumn{4}{|c|}{$\leq 65$-year population } & \multicolumn{4}{|c|}{$>65$-year population } \\
\hline & \multicolumn{2}{|c|}{$\begin{array}{l}\text { Placebo } \\
n=95\end{array}$} & \multicolumn{2}{|c|}{$\begin{array}{l}\text { Lipegfilgrastim } \\
n=197\end{array}$} & \multicolumn{2}{|c|}{$\begin{array}{l}\text { Placebo } \\
n=30\end{array}$} & \multicolumn{2}{|c|}{$\begin{array}{l}\text { Lipegfilgrastim } \\
n=53\end{array}$} \\
\hline & $n$ & $\%$ & $n$ & $\%$ & $n$ & $\%$ & $n$ & $\%$ \\
\hline At least 1 event & 81 & 85.3 & 164 & 84.1 & 25 & 83.3 & 46 & 86.8 \\
\hline Non-small cell lung cancer & 3 & 3.2 & 12 & 6.2 & 1 & 3.3 & 4 & 7.5 \\
\hline Anemia & 24 & 25.3 & 47 & 24.1 & 6 & 20.0 & 16 & 30.2 \\
\hline Leukopenia & 12 & 12.6 & 8 & 4.1 & 2 & 6.7 & 8 & 15.1 \\
\hline Neutropenia & 36 & 37.9 & 37 & 19.0 & 8 & 26.7 & 14 & 26.4 \\
\hline Thrombocytopenia & 7 & 7.4 & 23 & 11.8 & 3 & 10.0 & 9 & 17.0 \\
\hline Decreased appetite & 10 & 10.5 & 14 & 7.2 & 2 & 6.7 & 9 & 17.0 \\
\hline Hypokalemia & 2 & 2.1 & 12 & 6.2 & 1 & 3.3 & 8 & 15.1 \\
\hline Hypophosphatemia & 1 & 1.1 & 7 & 3.6 & 1 & 3.3 & 5 & 9.4 \\
\hline Dyspnea & 6 & 6.3 & 7 & 3.6 & 3 & 10.0 & 4 & 7.5 \\
\hline Pulmonary embolism & 0 & 0 & 2 & 1.0 & 2 & 6.7 & 1 & 1.9 \\
\hline Diarrhea & 3 & 3.2 & 3 & 1.5 & 1 & 3.3 & 4 & 7.5 \\
\hline Nausea & 19 & 20.0 & 46 & 23.6 & 8 & 26.7 & 13 & 24.5 \\
\hline Vomiting & 11 & 11.6 & 17 & 8.7 & 4 & 13.3 & 11 & 20.8 \\
\hline Alopecia & 35 & 36.8 & 78 & 40.0 & 7 & 23.3 & 23 & 43.4 \\
\hline Asthenia & 14 & 14.7 & 18 & 9.2 & 9 & 30.0 & 10 & 18.9 \\
\hline Chest pain & 6 & 6.3 & 12 & 6.2 & 2 & 6.7 & 2 & 3.8 \\
\hline Disease progression & 4 & 4.2 & 14 & 7.2 & 1 & 3.3 & 2 & 3.8 \\
\hline Fatigue & 5 & 5.3 & 10 & 5.1 & 1 & 3.3 & 6 & 11.3 \\
\hline Pyrexia & 4 & 4.2 & 12 & 6.2 & 2 & 6.7 & 0 & 0 \\
\hline Weight decreased & 2 & 2.1 & 7 & 3.6 & 0 & 0 & 5 & 9.4 \\
\hline
\end{tabular}

typical NSCLC population, $>75 \%$ of the population was aged $\leq 65$ years, and the overall incidence of FN in the ITT population was low [12].

In previously published studies of patients with lung cancer receiving a similar chemotherapy regimen, in which use of G-CSF was left to investigator discretion, a higher incidence of FN was reported (range of 10.4 to $13 \%$ ) relative to that observed in our study; however, it is likely that a less restrictive definition of FN was used in these studies (thereby leading to higher incidences of FN), as they were designed to assess the relative efficacy and safety of two different combination chemotherapy regimens rather than the effectiveness of G-CSF prophylaxis [13-15]. Moreover, in the present placebo-controlled study, it was necessary to exclude patients at high risk for $\mathrm{FN}$ due to ethical concerns, which was not the case in these previously published studies.

In the subset of patients aged $>65$ years, there was a difference in the incidence of $\mathrm{FN}$ in cycle 1 for patients receiving lipegfilgrastim $(0 \%)$ versus placebo $(13.3 \%)$, which was not observed in the younger subgroup or in the overall study populations (as published previously [12]). Although this difference in the incidence of FN was not statistically significant, it is notable considering the small number of patients in the elderly subgroup. The differences in patient demographics and baseline characteristics between the lipegfilgrastim and placebo groups within the $>65$-year population (e.g., 47/53 [89\%] vs 25/30 [83\%] male and mean time since diagnosis of 2.8 vs 5.4 months) are unlikely to have caused or contributed to the difference in neutropenia and febrile neutropenia between these groups. The $13.3 \%$ incidence of $\mathrm{FN}$ in the elderly subset of patients in the placebo group is in line with earlier published studies in which the same cisplatin/etoposide chemotherapy regimen, with or without G-CSF support, was used at similar dosages to the current study and patients at high risk for FN were not excluded, suggesting minimal treatment differences in the elderly versus overall populations [13-15]. Data for the other efficacy outcomes reported here were similar between age groups, except that lipegfilgrastim appeared to exert a greater effect in reducing the incidence of severe neutropenia in nonelderly versus elderly patients; however, the ability of lipegfilgrastim to reduce DSN was evident in both groups, persisting for no more than 1 day with lipegfilgrastim versus 2 to 3 days with placebo (consistent with the 
observed DSN data for the overall population [12]). Data for DSN are not available for the aforementioned published studies of cisplatin/etoposide, but one of the studies reported FN requiring hospitalization for a median of 6 days with a range of 4 to 24 days [13]. In clinical practice, the ability to reduce the duration of neutropenic events would be expected to have a positive effect on both treatment delivery, in terms of maintaining dose intensity and scheduled treatment intervals [16], and cost of care. Of note, in the placebo group, more delays for each cycle were to be expected and were indeed observed, due to neutropenia and febrile neutropenia developed during the previous cycle.

In both age groups, lipegfilgrastim was well tolerated, with a safety profile similar to that in patients receiving placebo. The most common AEs were consistent with the known toxicity profile of platinum-based chemotherapy. The most notable differences between lipegfilgrastim and placebo were in the incidences of hypokalemia and hypophosphatemia, which were higher among lipegfilgrastim recipients in both age groups and were more frequent in the elderly versus younger patients. The percentage of patients experiencing any AE was generally higher for elderly patients than for younger patients, which would be expected, considering that elderly patients are more likely to have comorbidities and be taking more medications than younger patients.

Limitations of this analysis and the interpretation of the results stem from the shortcomings that are inherent in post hoc subgroup analyses, including the reduced sample sizes when analyzing subgroups based on age or other characteristics.

\section{Conclusions}

In this placebo-controlled study, patients with an individual high risk of $\mathrm{FN}$ as assessed by the investigator were to be excluded because of ethical considerations. Therefore, it is not surprising that in the overall study population, the difference in $\mathrm{FN}$ incidence during cycle 1 versus placebo was not different. In the elderly subpopulation, which has a higher risk of developing myelosuppression and neutropenia, the FN incidence in cycle 1 in the placebo group $(13.3 \%)$ was in the range expected based on previously published studies [17]. The efficacy of lipegfilgrastim was demonstrated in this subpopulation (FN incidence of $0 \%$ ), which is more representative of the typical at-risk population scheduled to receive primary G-CSF prophylaxis. In patients with a higher risk, such as the elderly patients in this study, lipegfilgrastim reduced not only the duration of severe neutropenia but also the incidence of FN. However, due to the small number of patients in this elderly subpopulation, additional prospective studies that evaluate the clinical benefits of lipegfilgrastim in the elderly population with NSCLC, as well as benefits such as greater response, longer progression-free intervals, fewer hospitalizations, and reduced overall medical costs, are warranted.

Acknowledgments Medical writing assistance was provided by Laurie Orloski, PharmD, and Lisa Feder, PhD, of Peloton Advantage and was funded by Teva Branded Pharmaceutical Products R\&D, Inc. Teva provided a full review of the article.

\section{Compliance with ethical standards}

Funding This study was sponsored by Teva Branded Pharmaceutical Products R\&D, Inc., Frazer, PA.

Conflict of interests $\mathrm{CV}, \mathrm{IB}$, and $\mathrm{OG}$ have no competing interests. $\mathrm{AB}$, $\mathrm{UM}$, and PB hold stock or stock options in Teva Pharmaceuticals Industries Ltd. AB, UM, AL, and PB are employees of Teva Ratiopharm, Merckle $\mathrm{GmbH}$. All authors contributed substantially to the manuscript and provided final approval to submit this work.

\section{References}

1. Balducci L, Hardy CL, Lyman GH (2001) Hematopoietic growth factors in the older cancer patient. Curr Opin Hematol 8:170-187

2. National Comprehensive Cancer Network (2013) NCCN Clinical Practice Guidelines in Oncology. Senior Adult Oncology version 2.2014. http://www.nccn.org/professionals/physician gls/pdf/senior.pdf. Accessed 8 April 2016

3. Smith BD, Smith GL, Hurria A, Hortobagyi GN, Buchholz TA (2009) Future of cancer incidence in the United States: burdens upon the aging, changing nation. J Clin Oncol 27:2758-2765

4. Crawford J, Armitage J, Balducci L, Becker PS, Blayney DW, Cataland SR, Heaney ML, Hudock S, Kloth DD, Kuter DJ, Lyman GH, McMahon B, Rugo HS, Saad AA, Schwartzberg LS, Shayani S, Steensma DP, Talbott M, Vadhan-Raj S, Westervelt P, Westmoreland M, Dwyer M, Ho M (2013) Myeloid growth factors. J Natl Compr Cancer Netw 11:1266-1290

5. Crawford J, Caserta C, Roila F (2010) Hematopoietic growth factors: ESMO Clinical Practice Guidelines for the applications. Ann Oncol 21(suppl 5):v248-v251. doi:10.1093/annonc/mdq195

6. Smith TJ, Khatcheressian J, Lyman GH, Ozer H, Armitage JO, Balducci L, Bennett CL, Cantor SB, Crawford J, Cross SJ, Demetri G, Desch CE, Pizzo PA, Schiffer CA, Schwartzberg L, Somerfield MR, Somlo G, Wade JC, Wade JL, Winn RJ, Wozniak AJ, Wolff AC (2006) 2006 update of recommendations for the use of white blood cell growth factors: an evidence-based clinical practice guideline. J Clin Oncol 24:3187-3205. doi:10.1200/JCO.2006.06.4451

7. Zinzani PL, Pavone E, Storti S, Moretti L, Fattori PP, Guardigni L, Falini B, Gobbi M, Gentilini P, Lauta VM, Bendandi M, Gherlinzoni F, Magagnoli M, Venturi S, Aitini E, Tabanelli M, Leone G, Liso V, Tura S (1997) Randomized trial with or without granulocyte colony-stimulating factor as adjunct to induction VNCOP-B treatment of elderly high-grade non-Hodgkin's lymphoma. Blood 89:3974-3979

8. Balducci L, Al-Halawani H, Charu V, Tam J, Shahin S, Dreiling L, Ershler WB (2007) Elderly cancer patients receiving chemotherapy benefit from first-cycle pegfilgrastim. Oncologist 12:1416-1424. doi:10.1634/theoncologist.12-12-1416 
9. Lonquex: Summary of Product Characteristics. (2013) European Medicines Agency, London

10. Buchner A, Elsasser R, Bias P (2014) A randomized, double-blind, active control, multicenter, dose-finding study of lipegfilgrastim (XM22) in breast cancer patients receiving myelosuppressive therapy. Breast Cancer Res Treat 148:107-116. doi:10.1007/s10549014-3120-6

11. Bondarenko I, Gladkov OA, Elsaesser R, Buchner A, Bias P (2013) Efficacy and safety of lipegfilgrastim versus pegfilgrastim: a randomized, multicenter, active-control phase 3 trial in patients with breast cancer receiving doxorubicin/docetaxel chemotherapy. BMC Cancer 13:386-398. doi:10.1186/1471-2407-13-386

12. Volovat C, Bondarenko IM, Gladkov OA, Elsasser R, Buchner A, Bias P, Muller U (2015) Phase III, randomized, double-blind, placebo-controlled, multicenter study of lipegfilgrastim in patients with non-small cell lung cancer receiving myelosuppressive therapy. Springer Plus 4:316

13. Mavroudis D, Papadakis E, Veslemes M, Tsiafaki X, Stavrakakis J, Kouroussis C, Kakolyris S, Bania E, Jordanoglou J, Agelidou M, Vlachonicolis J, Georgoulias V (2001) A multicenter randomized clinical trial comparing paclitaxel-cisplatin-etoposide versus cisplatin-etoposide as first-line treatment in patients with smallcell lung cancer. Ann Oncol 12:463-470

14. Cardenal F, Lopez-Cabrerizo MP, Anton A, Alberola V, Massuti B, Carrato A, Barneto I, Lomas M, Garcia M, Lianes P, Montalar J, Vadell C, Gonzalez-Larriba JL, Nguyen B, Artal A, Rosell R (1999) Randomized phase III Study of gemcitabine-cisplatin versus etoposide-cisplatin in the treatment of locally advanced or metastatic non-small-cell lung cancer. J Clin Oncol 17:12-18

15. Hanna N, Bunn PA Jr, Langer C, Einhorn L, Guthrie T Jr, Beck T, Ansari R, Ellis P, Byrne M, Morrison M, Hariharan S, Wang B, Sandler A (2006) Randomized phase III trial comparing irinotecan/ cisplatin with etoposide/cisplatin in patients with previously untreated extensive-stage disease small-cell lung cancer. J Clin Oncol 24:2038-2043. doi:10.1200/JCO.2005.04.8595

16. Lyman GH (2006) Risks and consequences of chemotherapyinduced neutropenia. Clin Cornerstone 8(suppl 5):S12-S18

17. Minisini A, Spazzapan S, Crivellari D, Aapro M, Biganzoli L (2005) Incidence of febrile neutropenia and neutropenic infections in elderly patients receiving anthracycline-based chemotherapy for breast cancer without primary prophylaxis with colony-stimulating factors. Crit Rev Oncol Hematol 53:125-131. doi:10.1016/j. critrevonc.2004.11.003 